\title{
Quality of Life of Infants, Toddlers and Preschoolers with Seborrhoeic, Allergic Contact and Atopic Dermatitis Before and During COVID-19 Pandemic
}

\author{
Pavel V. Chernyshov (D) - Svitlana V. Vozianova · Olga V. Chubar
}

Received: August 13, 2021 / Accepted: September 15, 2021 / Published online: September 25, 2021

(C) The Author(s) 2021

\section{ABSTRACT}

Introduction: Different aspects of quality of life (QoL) of infants and children with atopic dermatitis (AD) are well studied but there is a lack of studies on seborrhoeic dermatitis (SD) and allergic contact dermatitis (ACD). The aim of this study was to compare the impact of SD, $\mathrm{ACD}$ and AD on young children. Parts of questionnaires were filled in during the COVID-19 pandemic and therefore we decided to check if the pandemic affected dermatology-specific health-related quality of life (HRQoL) in our patients.

Methods: In this cross-sectional study approved by the local ethics committee of the Kiev City Clinical Dermatovenereologic Hospital parents of children with SD, ACD and AD from birth to 4 years old from the same department of

P. V. Chernyshov $(\bowtie)$

Department of Dermatology and Venereology,

National Medical University, Bulvar Shevchenko,

13, Kiev 01601, Ukraine

e-mail: chernyshovpavel@ukr.net

S. V. Vozianova

Department of Dermatovenereology, Allergology, Clinical and Laboratory Immunology, Shupyk

National Healthcare University of Ukraine, Kiev, Ukraine

O. V. Chubar

Kiev City Clinical Dermatovenereologic Hospital, Kiev, Ukraine dermatology were asked to fill in the dermatology-specific questionnaire the Infants and Toddlers Dermatology Quality of Life (InToDermQoL). Diagnoses were based on clinical manifestations and anamnesis. The study was carried out from 2018 till 2021.

Results: The InToDermQoL questionnaire was filled in by 176 parents of children with SD, $\mathrm{ACD}$ and $\mathrm{AD}$. Mean total InToDermQoL scores were significantly higher in children with AD than in SD and ACD $(P<0.01)$. HRQoL of children with AD during the COVID-19 pandemic was significantly worse than before pandemic $\quad(41.30 \pm 24.40$ and $28.51 \pm 17.67$ respectively, $P=0.02$ ). Scores of the item on 'sleep problems' significantly decreased during the COVID-19 pandemic in children with SD $(1.19 \pm 1.01$ and $0.64 \pm 0.63, P<0.05)$, as did scores of the item on 'rejection by other children' in children with $\mathrm{AD}(0.96 \pm 0.98$ and $0.20 \pm 0.45, P<0.05)$.

Conclusions: To the best of our knowledge this is the first study on HRQoL of the youngest children with SD and ACD. In our study children with SD and ACD had comparable but lower impact of skin disease on their HRQoL than children with AD. The COVID-19 pandemic led to more severe HRQoL impairment in patients with AD visiting a dermatology department. 
Keywords: Seborrhoeic dermatitis; Allergic contact dermatitis; Atopic dermatitis; Quality of life; Children; COVID-19

\section{Key Summary Points}

\section{Why carry out this study?}

Quality of life of infants, toddlers and preschoolers with seborrhoeic and allergic contact dermatitis was not previously studied.

The COVID-19 pandemic may influence different aspects of quality of life in children with skin diseases.

This study aimed to compare the impact of seborrhoeic, allergic contact and atopic dermatitis on children from birth to 4 years of age from a single dermatology department and to check if the pandemic affected dermatology-specific healthrelated quality of life in our patients.

\section{What was learned from the study?}

Children from the same dermatology department with SD and ACD have comparable but lower impact of skin disease on their HRQoL than children with $\mathrm{AD}$.

The COVID-19 pandemic led to more severe HRQoL impairment in patients with $\mathrm{AD}$ visiting the dermatology department.

\section{INTRODUCTION}

Although differing in specific aspects of their epidemiology, etiology and pathobiology, seborrhoeic dermatitis (SD), allergic contact dermatitis (ACD) and atopic dermatitis (AD) are common in the paediatric population, and they often share common treatment approaches [1]. The overall age- and sex-adjusted prevalence of seborrhoeic dermatitis in one study was $10.0 \%$ in boys and 9.5\% in girls. This was highest in the first 3 months of life, decreasing rapidly by the age of 1 year, after which it slowly decreased over the next 4 years [2]. In children and adolescents from the general population the prevalence of ACD was $16.5 \%$ [3]. The overall point prevalence of $\mathrm{AD}$ symptoms in children ranged from $1.7 \%$ to $32.8 \%$ [4]. A recent international epidemiologic study showed that total $\mathrm{AD}$ prevalence was $12.1 \%$ among those aged 6 months to less than 6 years and $13.0 \%$ for those aged 6 years to less than 12 years [5]. In an epidemiologic study from Australia most children with SD (71.9\%) had disease classified as minimal to mild [2]. From 297 children with SD included in a Cochrane systematic review, disease severity was mild to moderate and only two participants had severe SD [6]. Recent epidemiologic data showed that the proportion of severe $\mathrm{AD}$ ranged from $0.9 \%$ to $14.9 \%$ except in Israel, where the proportion was approximately $25 \%$ among young children. Mild AD ranged from $35.8 \%$ to $72.3 \%$ and moderate $\mathrm{AD}$ from $28.8 \%$ to $55.0 \%$ [5]. We did not find epidemiologic data on disease severity in children with ACD.

Although different aspects of quality of life (QoL) of infants and children with AD are well studied in numerous publications, there is a lack of such studies on SD and ACD. One of the reasons was the absence of disease-specific health-related (HR) QoL instruments for SD and ACD and the absence of a dermatology-specific proxy HRQoL instrument for the youngest children [7-10]. Different skin diseases may affect patients' and their family members' QoL in different ways. Direct comparison of such a negative impact was possible in adults and children $4-5$ years of age by means of dermatology-specific HRQoL instruments [11-14]. Development of the dermatology-specific proxy HRQoL instrument the Infants and Toddlers Dermatology Quality of Life (InToDermQoL) made it possible to assess the impact of different skin diseases in children from their birth [15]. A validation study of the InToDermQoL showed similar total scores of $\mathrm{SD}, \mathrm{ACD}$ and $\mathrm{AD}$ in preschool children [16].

The COVID-19 pandemic has led to a significant decrease of paediatric dermatology 
consultations [17] and HRQoL in patients with skin diseases was found to worsen significantly compared to prepandemic studies [18].

The aim of this study was to compare impact of $\mathrm{SD}, \mathrm{ACD}$ and $\mathrm{AD}$ on children from birth to 4 years of age who were treated in the same dermatology department from 2018 till 2021. Parts of questionnaires were filled in during the COVID-19 pandemic and therefore we decided to check if the pandemic affected dermatologyspecific HRQoL in our patients.

\section{METHODS}

In this cross-sectional study parents of children with SD, ACD and AD from birth to 4 years old from the department of dermatology of the Kiev City Clinical Dermatovenereologic Hospital were asked on a voluntary base to fill in the InToDermQoL questionnaire. Diagnosis of skin diseases was confirmed by a dermatologist in all cases. Diagnoses were based on clinical manifestations and anamnesis. Diagnosis of AD was based on Hanifin and Rajka criteria [19]. Disease severity was graded as mild, moderate or severe on the basis of subjective assessment by the same dermatologists. Children that had manifestations of two or more different skin diseases or those who had also manifest non-skin diseases were excluded from the study. The study was carried out from 2018 till 2021.

QoL is a broad multidimensional concept that includes subjective evaluations of both positive and negative aspects of life [20].

The concept of health-related quality of life (HRQoL) and its determinants have evolved to encompass those aspects of overall QoL that can be clearly shown to affect health-either physical or mental. On the individual level, HRQoL includes physical and mental health perceptions (e.g. energy level, mood) and their correlates-including health risks and conditions, functional status, social support and socioeconomic status [21]. Generic, dermatology-specific and disease-specific instruments can be used to measure HRQoL in paediatric dermatology. Dermatology-specific instruments may be used in different skin diseases. The InToDermQoL is the first dermatology-specific proxy HRQoL instrument for children $0-4$ years old with skin diseases. In order to avoid the problem of crosscultural inequivalence, focus groups work and pilot tests were organized simultaneously in all national centres of the project. There are 10 national language versions of the InToDermQoL. The InToDermQoL showed good comprehensibility, clarity, acceptance, internal consistency, test-retest reliability, convergent and discriminant validity. The InToDermQoL consists of three versions: 10 items for children under 1 year of age, 12 items for children from 1 to 2 years of age and 15 items for children of 3-4 years of age. Responses of the InToDermQoL questionnaire are on a 4-point scale, from 0 to 3 . The total score is calculated by summing the score of each question. Maximum total score for children under 1 year of age is 30 . Maximum total score for children from 1 to 2 years of age is 36 . Maximum total score for children of $3-4$ years of age is $45[15,16]$. To compare results of different age groups, the percentages from the total InToDermQoL scores were calculated.

The word "quimp", meaning "QoL impairment", was recently proposed [22]. The EADV Task Force on QoL and Patient Oriented Outcomes recommends the word "quimp" for routine clinical and research use [23] and we used it in our present study.

Ethical permission for the study was granted by the local ethical committee of the Kiev City Clinical Dermatovenereologic Hospital. Parents of children with skin diseases from the department of dermatology of the Kiev City Clinical Dermatovenereologic Hospital gave their consent to participate in this study.

Data were presented as mean \pm standard deviation of the mean. An unpaired $t$ test with Welch correction (two-tailed $P$ value) was used to compare continuous variables, Spearman correlation coefficient was used to measure correlation between scores and Fisher's exact test (two-sided) was used to examine the significance of the association between the two kinds of classification. The results were considered significant if $P<0.05$. 


\section{RESULTS}

The InToDermQoL questionnaire was filled in by 176 parents of children with SD, ACD and $\mathrm{AD}$. Mean age in months, severity grades and number of boys and girls for each skin disease are presented in Table 1.

Mean total InToDermQoL scores as a percentage were significantly higher in children with AD than in SD and ACD (Table 2). The highest scored InToDermQoL items in children with SD were 'itching or scratching', 'sleep problems', 'mood changes' and 'problems with treatment'. The highest scored InToDermQoL items in children with ACD were 'restrictions and limitations', 'itching or scratching' and 'mood changes'. The highest scored InToDermQoL items in children with $\mathrm{AD}$ were 'itching or scratching', 'restrictions and limitations', 'sleep problems', 'mood changes' and 'problems with treatment'. Separate InToDermQoL item scores on 'itching or scratching', 'bathing problems' and 'problems with dressing/undressing' were significantly lower in children with SD and ACD. Scores of the item on 'bleeding' were lower in children with SD and $\mathrm{ACD}$ than in children with $\mathrm{AD}$ but the difference between $\mathrm{AD}$ and ACD did not reach the level of statistical significance. The scores of the items on 'problems with treatment' and 'child's tiredness' were significantly higher in children with $\mathrm{AD}$ than in children with ACD.
Item scores on 'sleep problems' were significantly lower in children with ACD than in children with SD and AD.

Correlations of total InToDerQoL scores, disease severity and age are presented in Table 3. All separate InToDermQoL items except three items for 3-4-year-old children and the item on 'tiredness' significantly correlated with diseases severity grades in children with AD. All separate InToDermQoL items except items on 'bathing problems', 'problems with dressing/undressing', 'problems during physical activity' and 'problems with treatment' significantly correlated with diseases severity grades in children with SD. The only two InToDermQoL items correlated with diseases severity grades in children with ACD were 'itching or scratching' and 'sleep problems' (Table 4).

There were significantly more children with mild AD (31 and 1, $P<0.01)$ and fewer with severe $\mathrm{AD}(5$ and $10, P<0.01)$ before the start of the COVID-19 pandemic. HRQoL of children with $\mathrm{AD}$ during the COVID-19 pandemic was significantly worse than before the pandemic (mean total InToDermQoL scores were $41.30 \pm 24.40$ and $28.51 \pm 17.67$ respectively, $P=0.02$ ). Three separate InToDermQoL items had a more severe impact on children with AD during the COVID-19 pandemic: 'bleeding' $(0.14 \pm 0.43$ and $0.90 \pm 0.90, P<0.001)$, 'pain' $(0.43 \pm 0.76$ and $1.17 \pm 1.10, \quad P<0.01)$ and 'feeding problems' $(0.35 \pm 0.68$ and

Table 1 Mean age in months, severity grades and number of boys and girls with seborrhoeic dermatitis, allergic contact dermatitis and atopic dermatitis

\begin{tabular}{llll}
\hline & Seborrhoeic dermatitis & Allergic contact dermatitis & Atopic dermatitis \\
\hline Age in months & $6.46 \pm 10.13^{*}$ & $19.15 \pm 12.04$ & $23.64 \pm 16.14$ \\
Boys & 35 & 15 & 44 \\
Girls & 22 & 12 & 48 \\
Severity grades & & & \\
Mild & $13(22.81 \%)$ & $4(14.81 \%)$ & $32(34.78 \%)$ \\
Moderate & $38(66.67 \%)$ & $22(81.48 \%)$ & $45(48.91 \%)$ \\
Severe & $6(10.52 \%)$ & $1(3.70 \%)$ & $15(16.30 \%)$ \\
\hline
\end{tabular}

${ }^{*}$ Age of children with seborrhoeic dermatitis was lower than in allergic contact dermatitis and atopic dermatitis $(P<0.01$ for both) 
Table 2 Total Infants and Toddlers Dermatology Quality of Life (InToDermQoL) scores and its separate item scores of children with seborrhoeic dermatitis, allergic contact dermatitis and atopic dermatitis

\begin{tabular}{llll}
\hline & $\begin{array}{l}\text { Seborrhoeic } \\
\text { dermatitis }\end{array}$ & $\begin{array}{l}\text { Allergic contact } \\
\text { dermatitis }\end{array}$ & $\begin{array}{l}\text { Atopic } \\
\text { dermatitis }\end{array}$ \\
\hline Total InToDermQoL scores (\%) & $23.98 \pm 16.67^{* *}$ & $22.41 \pm 14.01^{* *}$ & $32.54 \pm 20.78$ \\
Child's itching or scratching & $1.47 \pm 1.02^{*}$ & $1.33 \pm 1.11^{*}$ & $1.83 \pm 0.85$ \\
$\begin{array}{l}\text { Child's bleeding (from injured skin and/or } \\
\text { mucosa) }\end{array}$ & $0.18 \pm 0.47^{*}$ & $0.19 \pm 0.40$ & $0.38 \pm 0.71$ \\
Child's pain & $0.72 \pm 0.98$ & $0.52 \pm 0.85$ & $0.66 \pm 0.94$ \\
Sleep problems & $1.11 \pm 0.96$ & $0.59 \pm 0.64^{* * *}$ & $1.36 \pm 0.92$ \\
Mood changes & $1.05 \pm 0.95$ & $1.15 \pm 0.99$ & $1.30 \pm 0.90$ \\
Bathing problems & $0.49 \pm 0.89^{* *}$ & $0.33 \pm 0.68^{* * *}$ & $0.99 \pm 1.01$ \\
Problems with dressing/undressing & $0.46 \pm 0.83^{* *}$ & $0.44 \pm 0.70^{* *}$ & $0.90 \pm 1.02$ \\
Feeding problems & $0.25 \pm 0.66$ & $0.44 \pm 0.80$ & $0.47 \pm 0.79$ \\
Child's problems during physical activity & $0.42 \pm 0.71$ & $0.33 \pm 0.62$ & $0.57 \pm 0.88$ \\
Child's problems with treatment & $1.05 \pm 0.87$ & $0.67 \pm 0.88^{* *}$ & $1.27 \pm 1.05$ \\
Child's tiredness & - & $0.11 \pm 0.32^{* *}$ & $0.49 \pm 0.68$ \\
Restrictions and limitations & - & $1.74 \pm 1.20$ & $1.50 \pm 1.04$ \\
\hline
\end{tabular}

Lower than atopic dermatitis: ${ }^{*} P<0.05,{ }^{* *} P<0.01,{ }^{* *} P<0.001$

Lower than seborrhoeic dermatitis: ${ }^{\#} P<0.01$

$0.76 \pm 0.95, P<0.05)$. Scores of the item on 'rejection by other children' in children with AD significantly decreased during the COVID19 pandemic $(0.96 \pm 0.98$ and $0.20 \pm 0.45$, $P<0.05)$. Scores of the item on 'sleep problems' significantly decreased during the COVID-19 pandemic in children with SD $(1.19 \pm 1.01$ and $0.64 \pm 0.63, P<0.05)$. There were no changes in the InToDermQoL total scores or its separate item scores during the COVID-19 pandemic in children with ACD.

\section{DISCUSSION}

In our study children with $\mathrm{AD}$ had worse HRQoL than children with SD and ACD. Itch had a higher impact on children with AD than on children with SD and ACD. Pain had a less severe impact than itch in all three groups. Restrictions and limitations had a very high impact on HRQoL of children with SD, ACD and AD. Sleep problems in children with ACD were much less severe than in SD and AD. We did not find other studies on sleep problems in children with ACD. It is interesting that disease severity assessed by dermatologist significantly correlated with total InToDermQoL scores in children with $\mathrm{SD}$ and $\mathrm{AD}$ but did not correlate significantly in children with ACD. We can speculate that it is related to the more chronic course of $\mathrm{AD}$ and SD. However, 'itching and scratching' and 'sleep problems' significantly correlated with disease severity in children with ACD. Our data shows that although sleep problems did not have a major impact on HRQoL in children with ACD this impact increased with progression of clinical signs.

High scores of the item on 'restrictions and limitations' in children with ACD and AD are a result of the so-called avoiding strategy. Difficulties in adopting suitable avoidance 
Table 3 Correlations of total Infants and Toddlers Dermatology Quality of Life (InToDermQoL) scores, disease severity and age in months

\begin{tabular}{|c|c|c|c|}
\hline Correlations (Spearman $r$ ) & $\begin{array}{l}\text { Seborrhoeic dermatitis } \\
(n=57)\end{array}$ & $\begin{array}{l}\text { Allergic contact dermatitis } \\
(n=27)\end{array}$ & $\begin{array}{l}\text { Atopic dermatitis } \\
(n=92)\end{array}$ \\
\hline \multirow{2}{*}{$\begin{array}{l}\text { Total score with disease } \\
\text { severity }\end{array}$} & $r=0.47$ & $r=0.27$ & $r=0.58$ \\
\hline & $P<0.001$ & $P=0.17$ & $P<0.001$ \\
\hline \multirow{2}{*}{$\begin{array}{l}\text { Total score with age in } \\
\text { months }\end{array}$} & $r=0.17$ & $r=-0.10$ & $r=-0.11$ \\
\hline & $P=0.21$ & $P=0.63$ & $P=0.29$ \\
\hline \multirow{2}{*}{$\begin{array}{l}\text { Age in months with disease } \\
\text { severity }\end{array}$} & $r=0.02$ & $r=-0.18$ & $r=-0.14$ \\
\hline & $P=0.87$ & $P=0.38$ & $P=0.18$ \\
\hline
\end{tabular}

behaviour by patients who were diagnosed with ACD is a well-known problem [24]. Therefore a high score for 'restrictions and limitations' in children with ACD may reflect an adequate avoiding strategy provided by their parents. Meanwhile, too severe and often unnecessary restrictions are still typical for children with $\mathrm{AD}$ $[25,26]$. There is no evidence for a benefit in the use of elementary or few food-restricted diets in unselected patients with AD. Epidemiological studies have shown a significant association between the diversity of foods given in the first year of life and protection from $\mathrm{AD}$ [27]. We therefore recommend to include a discussion on avoiding strategies in consultations of children with $\mathrm{AD}$ and their parents.

Quality of life of family members of children with skin diseases may be severely affected and is related to patients' HRQoL [28-30]. Parents of school children with skin disease are generally less stressed, tired and exhausted than parents of preschool children with skin disease [31, 32]. Fears and restrictions related to the COVID-19 pandemic may increase the general impact on parents' QoL. Parents of children with skin diseases during the COVID-19 pandemic should receive information on effective preventive measures and access to online or phone consultations if needed. Family members may also benefit from mutual activities (i.e. changes of behaviour, religious/spiritual well-being, music, diet, etc.) and, of course, from good and supportive relations inside the family $[33,34]$.
The COVID-19 pandemic led to an increase of children with severe $\mathrm{AD}$ and more severe HRQoL impairment in the dermatology department. The items on 'bleeding', 'pain' and 'feeding problems' were scored significantly higher by parents of children with $\mathrm{AD}$ during the COVID-19 pandemic. It looks like patients with more severe clinical course of $\mathrm{AD}$ more often complain about pain. A recent review on itch and pain in $\mathrm{AD}$ contains information that up to $40 \%$ of patients with $\mathrm{AD}$ report skin pain [35]. In contrast, the item 'rejection by other children' in children with $\mathrm{AD}$ and 'sleep problems' in SD had a less severe impact than before the pandemic. Less rejection by others may be explained by decrease of social interaction caused by the pandemic. The child's problems in the period from early infancy till 3 years of age depend on parental exhaustion, emotional distress, and security of the mother-child attachment [36]. Thus, we can speculate that less severe 'sleep problems' in children with SD during the COVID-19 pandemic in our study may be a result of parental psychological status improvement.

To the best of our knowledge, this is the first study on HRQoL of the youngest children with SD and ACD. There are a wide range of potential benefits of HRQoL assessment and its use in clinical practice [37]. We are planning to organize international studies to have a better understanding of HRQoL impairment in children with SD and ACD. It is also important to perform studies on gender differences where 
Table 4 Correlations of separate Infants and Toddlers Dermatology Quality of Life (InToDermQoL) item scores with disease severity of children with seborrhoeic dermatitis, allergic contact dermatitis and atopic dermatitis

\begin{tabular}{|c|c|c|c|}
\hline $\begin{array}{l}\text { Correlations } \\
(\text { Spearman } r)\end{array}$ & $\begin{array}{l}\text { Seborrhoeic } \\
\text { dermatitis }\end{array}$ & $\begin{array}{l}\text { Allergic contact } \\
\text { dermatitis }\end{array}$ & $\begin{array}{l}\text { Atopic } \\
\text { dermatitis }\end{array}$ \\
\hline \multirow[t]{2}{*}{ Child's itching or scratching } & $r=0.41$ & $r=0.48$ & $r=0.48$ \\
\hline & $P<0.01$ & $P<0.01$ & $P<0.001$ \\
\hline \multirow[t]{2}{*}{ Child's bleeding (from injured skin and/or mucosa) } & $r=0.35$ & $r=0.11$ & $r=0.54$ \\
\hline & $P<0.01$ & $P=0.59$ & $P<0.001$ \\
\hline \multirow[t]{2}{*}{ Child's pain } & $r=0.36$ & $r=0.18$ & $r=0.53$ \\
\hline & $P<0.001$ & $P=0.37$ & $P<0.001$ \\
\hline \multirow[t]{2}{*}{ Sleep problems } & $r=0.30$ & $r=0.43$ & $r=0.37$ \\
\hline & $P<0.05$ & $P=0.02$ & $P<0.001$ \\
\hline \multirow[t]{2}{*}{ Mood changes } & $r=0.29$ & $r=0.25$ & $r=0.38$ \\
\hline & $P<0.05$ & $P=0.20$ & $P<0.001$ \\
\hline \multirow[t]{2}{*}{ Bathing problems } & $r=0.02$ & $r=0.15$ & $r=0.43$ \\
\hline & $P=0.84$ & $P=0.45$ & $P<0.001$ \\
\hline \multirow[t]{2}{*}{ Problems with dressing/undressing } & $r=0.26$ & $r=0.15$ & $r=0.35$ \\
\hline & $P=0.05$ & $P=0.45$ & $P<0.001$ \\
\hline \multirow[t]{2}{*}{ Feeding problems } & $r=0.32$ & $r=-0.24$ & $r=0.32$ \\
\hline & $P=0.01$ & $P=0.22$ & $P<0.01$ \\
\hline \multirow[t]{2}{*}{ Child's problems during physical activity } & $r=0.17$ & $r=-0.08$ & $r=0.32$ \\
\hline & $P=0.20$ & $P=0.70$ & $P<0.01$ \\
\hline \multirow[t]{2}{*}{ Child's problems with treatment } & $r=0.21$ & $r=0.32$ & $r=0.54$ \\
\hline & $P=0.11$ & $P=0.10$ & $P<0.001$ \\
\hline \multirow[t]{2}{*}{ Child's tiredness } & - & $r=0.12$ & $r=0.21$ \\
\hline & & $P=0.62$ & $P=0.08$ \\
\hline \multirow[t]{2}{*}{ Restrictions and limitations } & - & $r=0.02$ & $r=0.27$ \\
\hline & & $P=0.94$ & $P=0.03$ \\
\hline \multirow{2}{*}{$\begin{array}{l}\text { Other people's questions about your child's skin } \\
\text { disease }\end{array}$} & - & - & $r=0.18$ \\
\hline & & & $P=0.37$ \\
\hline \multirow[t]{2}{*}{ Child's feeling of being different } & - & - & $r=0.30$ \\
\hline & & & $P=0.12$ \\
\hline \multirow[t]{2}{*}{ Rejection by other children } & - & - & $r=0.20$ \\
\hline & & & $P=0.32$ \\
\hline
\end{tabular}


participants are well matched by factors other than gender, like what was organized for $\mathrm{AD}$ $[38,39]$.

This study has several limitations. Recruitment of the patients was limited to a single dermatology department and patients were not artificially balanced by age, disease severity and number of patients per diagnosis. Survey results were collected before and during the COVID-19 pandemic. Distinct subjectivity is present in the assessment of disease severity grades. It was previously shown that some children with SD may later develop classic features of $\mathrm{AD}$ and some authors even called into question the existence of infantile SD as an independent clinical diagnosis [40].

\section{CONCLUSIONS}

In our study children with SD and ACD experienced a comparable but lower impact of skin disease on their HRQoL than children with AD. The COVID-19 pandemic led to more severe HRQoL impairment in patients with AD visiting the dermatology department.

\section{ACKNOWLEDGEMENTS}

We thank the participants of the study.

Funding. No funding or sponsorship was received for this study or publication of this article.

Authorship. All named authors meet the International Committee of Medical Journal Editors (ICMJE) criteria for authorship for this article, take responsibility for the integrity of the work as a whole, and have given their approval for this version to be published.

Author Contributions. Pavel V. Chernyshov-concept and design, statistical analysis, drafting the manuscript; Svitlana V. Vozianova - data collection, drafting the manuscript; Olga V. Chubar - concept and design, data collection, drafting the manuscript, critical review of the text. All authors provided critical feedback and helped shape the research, analysis and manuscript.

Disclosures. Pavel V. Chernyshov, Svitlana V. Vozianova and Olga V. Chubar have nothing to disclose.

Compliance with Ethics Guidelines. Ethical permission for the study was granted by the local ethical committee of the Kiev City Clinical Dermatovenereologic Hospital. Parents of children with skin diseases from the department of dermatology of the Kiev City Clinical Dermatovenereologic Hospital gave their consent to participate in this study.

Data Availability. The datasets generated during and/or analyzed during the current study are available from the corresponding author on reasonable request.

Open Access. This article is licensed under a Creative Commons Attribution-NonCommercial 4.0 International License, which permits any non-commercial use, sharing, adaptation, distribution and reproduction in any medium or format, as long as you give appropriate credit to the original author(s) and the source, provide a link to the Creative Commons licence, and indicate if changes were made. The images or other third party material in this article are included in the article's Creative Commons licence, unless indicated otherwise in a credit line to the material. If material is not included in the article's Creative Commons licence and your intended use is not permitted by statutory regulation or exceeds the permitted use, you will need to obtain permission directly from the copyright holder. To view a copy of this licence, visit http:// creativecommons.org/licenses/by-nc/4.0/.

\section{REFERENCES}

1. Fleischer $\mathrm{AB}$ Jr. Diagnosis and management of common dermatoses in children: atopic, seborrheic, and contact dermatitis. Clin Pediatr (Phila). 2008;47:332-46. 
2. Foley P, Zuo Y, Plunkett A, Merlin K, Marks R. The frequency of common skin conditions in preschoolaged children in Australia: seborrheic dermatitis and pityriasis capitis (cradle cap). Arch Dermatol. 2003;139:318-22.

3. Alinaghi F, Bennike NH, Egeberg A, Thyssen JP, Johansen JD. Prevalence of contact allergy in the general population: a systematic review and metaanalysis. Contact Dermatitis. 2019;80:77-85.

4. Bylund S, von Kobyletzki LB, Svalstedt M, Svensson $\AA$. Prevalence and incidence of atopic dermatitis: a systematic review. Acta Derm Venereol. 2020;100: adv00160.

5. Silverberg JI, Barbarot S, Gadkari A, et al. Atopic dermatitis in the pediatric population: a cross-sectional, international epidemiologic study. Ann Allergy Asthma Immunol. 2021;126:417-28.e2.

6. Victoire A, Magin P, Coughlan J, van Driel ML. Interventions for infantile seborrhoeic dermatitis (including cradle cap). Cochrane Datab Syst Rev. $2019 . \quad$ https://doi.org/10.1002/14651858. CD011380.pub2.

7. Chernyshov PV, Tomas-Aragones L, Manolache L, et al. Quality of life measurement in atopic dermatitis. Position paper of the European Academy of Dermatology and Venereology (EADV) Task Force on quality of life. J Eur Acad Dermatol Venereol. 2017;31:576-93.

8. Chernyshov PV, Jiráková A, Hercogová J. Comparative study of the quality of life of children with atopic dermatitis from Ukraine and the Czech Republic. J Eur Acad Dermatol Venereol. 2011;25: 1483-4.

9. Chernyshov PV. Dermatological quality of life instruments in children. G Ital Dermatol Venereol. 2013;148:277-85.

10 Chernyshov P, de Korte J, Tomas-Aragones L, LewisJones S. EADV Quality of Life Task Force. EADV Taskforce's recommendations on measurement of health-related quality of life in paediatric dermatology. J Eur Acad Dermatol Venereol. 2015;29: 2306-16.

11. Sampogna F, Tabolli S, Abeni D. Impact of different skin conditions on quality of life. G Ital Dermatol Venereol. 2013;148:255-61.

12. Dalgard FJ, Gieler U, Tomas-Aragones L, et al. The psychological burden of skin diseases: a cross-sectional multicenter study among dermatological out-patients in 13 European countries. J Invest Dermatol. 2015;135:984-91.
13. Chernyshov PV. Health-related quality of life in adult atopic dermatitis and psoriatic patients matched by disease severity. G Ital Dermatol Venereol. 2016;151:37-43.

14. Manzoni AP, Pereira RL, Townsend RZ, Weber MB, Nagatomi AR, Cestari TF. Assessment of the quality of life of pediatric patients with the major chronic childhood skin diseases. An Bras Dermatol. 2012;87:361-8.

15. Chernyshov PV, Boffa MJ, Corso R, et al. Creation and pilot test results of the dermatology-specific proxy instrument: the Infants and toddlers dermatology quality of life. J Eur Acad Dermatol Venereol. 2018;32:2288-94.

16. Chernyshov PV, Sampogna F, Pustišek N, et al. Validation of the dermatology-specific proxy instrument the Infants and Toddlers Dermatology Quality of Life. J Eur Acad Dermatol Venereol. 2019;33:1405-11.

17. Uzuncakmak TK, Bayazit S, Askin O, Engin B, Kutlubay Z. Inpatient dermatology consultations during COVID 19 pandemic in a tertiary referral center. Dermatol Ther. 2020;33:e13883.

18. Daye M, Temiz SA, Ișık B, Dursun R, Ataseven A. Evaluation of the effect of COVID-19 pandemic on dermatological diseases with dermatological quality life index. Dermatol Ther. 2020;33:e14368.

19. Hanifin GM, Rajka G. Diagnostic feature of atopic dermatitis. Acta Derm Venereol. 1980;92:44-7.

20 The WHOQOL Group. The World Health Organization Quality of Life Assessment (WHOQOL). Development and psychometric properties. Soc Sci Med. 1998;46:1569-85.

21. National Center for Chronic Disease Prevention and Health Promotion, Division of Population Health. https://www.cdc.gov/hrqol/concept.htm. Accessed Oct 31, 2018.

22. Finlay AY. Quimp: a word meaning "quality of life impairment." Acta Derm Venereol. 2017;97:546-7.

23. Chernyshov PV, Linder MD, Pustišek N, et al. Quimp (quality of life impairment): an addition to the quality of life lexicon. J Eur Acad Dermatol Venereol. 2018;32:e181-2.

24. Simonsen $\mathrm{AB}$, Sommerlund M, Deleuran M, Mortz CG, Johansen JD. Course of skin symptoms and quality of life in children referred for patch testing-a long-term follow-up study. Acta Derm Venereol. 2015;95:206-10. 
25. Sinagra JL, Bordignon V, Ferraro C, et al. Unnecessary milk elimination diets in children with atopic dermatitis. Pediatr Dermatol. 2007;24:1-6.

26. Silverberg NB, Lee-Wong M, Yosipovitch G. Diet and atopic dermatitis. Cutis. 2016;97:227-32.

27. Wollenberg A, Barbarot S, Bieber T, et al. Consensus-based European guidelines for treatment of atopic eczema (atopic dermatitis) in adults and children: part I. J Eur Acad Dermatol Venereol. 2018;32:657-82.

28. Chernyshov PV. The evolution of quality of life assessment and use in dermatology. Dermatology. 2019;235:167-74.

29. Sampogna F, Finlay AY, Salek SS, et al. Measuring the impact of dermatological conditions on family and caregivers: a review of dermatology-specific instruments. J Eur Acad Dermatol Venereol. 2017;31:1429-39.

30. Chernyshov PV, Kaliuzhna LD, Reznikova AA, Basra MK. Comparison of the impairment of family quality of life assessed by disease-specific and dermatology-specific instruments in children with atopic dermatitis. J Eur Acad Dermatol Venereol. 2015;29:1221-4.

31. Chernyshov PV, Jirakova A, Ho RC, et al. An international multicenter study on quality of life and family quality of life in children with atopic dermatitis. Indian J Dermatol Venereol Leprol. 2013;79:52-8.

32. Chernyshov PV, Ho RC, Monti F, et al. An international multi-center study on self-assessed and family quality of life in children with atopic dermatitis. Acta Dermatovenerol Croat. 2015;23: 247-53.

33. Chernyshov PV, Tomas-Aragones L, Augustin M, et al. Position statement of the European Academy of Dermatology and Venereology Task Force on quality of life and patient oriented outcomes on quality of life issues in dermatologic patients during the COVID-19 pandemic. J Eur Acad Dermatol Venereol. 2020;34:1666-71.

34 Finlay AY, Chernyshov PV, Tomas Aragones L, et al. Methods to improve quality of life, beyond medicines: position statement of the European Academy of Dermatology and Venereology Task Force on Quality of Life and Patient Oriented Outcomes. J Eur Acad Dermatol Venereol. 2021;35:318-28.

35. Misery L, Belloni Fortina A, El Hachem M, et al. A position paper on the management of itch and pain in atopic dermatitis from the International Society of Atopic Dermatitis (ISAD)/Oriented Patient-Education Network in Dermatology (OPENED) task force. J Eur Acad Dermatol Venereol. 2021;35: 787-96.

36. Chernyshov PV. Stigmatization and self-perception in children with atopic dermatitis. Clin Cosmet Investig Dermatol. 2016;9:159-66.

37. Finlay AY, Salek MS, Abeni D, et al. Why quality of life measurement is important in dermatology clinical practice: an expert-based opinion statement by the EADV Task Force on Quality of Life. J Eur Acad Dermatol Venereol. 2017;31:424-31.

38. Chernyshov PV. Gender differences in health-related and family quality of life in young children with atopic dermatitis. Int J Dermatol. 2012;51: 290-4.

39. Chernyshov PV, Ho RC, Monti F, et al. Gender differences in self-assessed health-related quality of life in children with atopic dermatitis. J Clin Aesthet Dermatol. 2016;9:19-24.

40. Alexopoulos A, Kakourou T, Orfanou I, Xaidara A, Chrousos G. Retrospective analysis of the relationship between infantile seborrheic dermatitis and atopic dermatitis. Pediatr Dermatol. 2014;31: 125-30. 